\title{
The Optimization for the Technology Management in the Development of the Front-end Business
}

\author{
Lingyuan Li \\ New York University, New York, USA \\ II3291@nyu.edu
}

Keywords: Technology management; Front-end business development; Optimization

\begin{abstract}
The technology innovation has been changing every day. However, that does not necessarily live up to what we expect. The maximization of the technology innovation value, esp. in the development of front-end business, needs the guarantee from technology management. And the optimization of the strategies in managing the development of front-end business can be helpful in making an overall plan and coordinating successfully among different posts in the department. The technology management can improve the efficiency in the development of front-end business.
\end{abstract}

\section{Introduction}

The development of computer and information science in the 21th century has brought human society into a new era. However, the innovation of technology does not necessarily result in the economic growth. The practice of the developed countries such as the U.S. and Japan, indicates that the technological innovation is not the only one factor to promote the development of economics, for it is still necessary to combine with the technical transformation and the operating management in order to maximize the value of the technological innovation[1]. The computer technology and the information science have changed very quickly, and if these cannot have close integration with many aspects such as market and users, it is very difficult for technological innovation to make immediate economics sense for the society[2]. For example, in the development of the front-end system, it is not easy to maximize the technological innovation without a reasonable comprehensive management, for this process is characteristic with diversified technical posts and user-orientation. So, it is worth studying further.

\section{The Research State of the Technological Management at Home and Abroad}

The rapid development of technology is leading us into an age of the Internet, and the optimization of the management not only makes the technology develop quickly, but also maximizes its value[3]. The development and application of technology innovation has been paid great attention abroad since Joseph Alois Schumpeter created the term[4]. It is assumed that the effective way to maximize the value of technological innovation is on the technology. According to Betz, the technology management is to improve the capacity of product production of a company[5]. In the two books of "Technology Management: Text and International Cases"[6] and "Wharton on Managing Emerging Technologies"[7], the economists have made close study in the field of management. They point out that all the activities to the technology should be involved into the management, which includes not only technology strategy, technology development, technology forecast, new technology evaluation, but also the obstacles in the development of products and the use of technology, and the forms of design and organization. Experts emphasize the importance of human resource and organizational factors in the development of technology. They argue that the practice of the management, a technical supervisor should not only make technology distribution among his team, give instruction from the perspective of technology, but also conduct technical supervision. The supervisor should make good use of his/her own knowledge in the field of technology to improve the efficiency of the entire team in order to carry out the technical task[8]. Since 2000, the technology management has also received a lot of attention in China. For instance, in the study of "The Management in Technology Innovation"[9], "The Technology Management"[10] and "The 
Frontier Research Report on Technology Management and Technology Innovation"[11], Chinese economists have achieved a lot on the value maximization of the technology innovation. All the study from both home and abroad, undoubtedly, can promote the development of technology innovation.

\section{The Structural System of Front-end Department}

The posts of the professional staff who are involved in front-end business demonstrate not only diversified characteristics but also close connection with each other. In addition to the team leader, basically, the department of front-end provides different posts such as interaction designer, visual designer and front-end development engineer. Although their areas of expertise are so different, their jobs in the development of front-end business have very close relationship with each other. Theoretically, after the department gets a project, the interaction designer, based on product functions and the requirements of users, not only analyzes business logic and business process but also considers the factors like market, technology and commercial demand to design a prototype. And then, this low-fidelity prototype will be rendered with visual effects by the visual designer in the design framework, who makes good use of his/her own professional knowledge about aesthetics, art and fashion trends to create its marketing form. In the last process, front-end development engineers will realize all the visual effects and front-end functions of the product according to the high-fidelity design. However, in the practice of the development cycle, the project procedures cannot be always carried out fluidly: If some job in one procedure cannot be done within the time, it will delay the schedule of the next procedure and even the whole project; the professional staff need a communication with each other to get reasonable suggestions so that they can improve their job. For example, If the front-end developer is unable to realize functions of the design, the interaction designer, according to the feedback, has to adjust his/her work to make it easier for developers to implement; If the high-fidelity design by the visual designer is not acceptable, they may need to readjust the color scheme or the animation. From the above description of the structural system, we can see that the professional posts and technology are all diversified, which, obviously, increases more difficulties to the management. So, it is quite necessary to maximize the value of technology innovation by optimizing the management.

\section{The Strategies of Technology Management in the Development of the Front-end Business}

Emphasizing the Diversified Characteristics of the Department. The department of front-end is characteristics with diversity and involves many different areas of expertise. Also, it is user-orientated which requires all the professional staff should become very flexible and sensitive to the changes. As a leader, he/she should pay more attention to this complex situation. Additionally, it is the leader's responsibility to encourage all the staff to communicate with each other, which is very helpful for them to cooperate.

Making Overall Arrangement in Managing the Business Development. As a leader of a team, he/she should make a plan in the whole process of development such as distributing tasks, checking progress, and esp. enhancing the communication among the staff. In the system of technology management, all the management activities regards the technology as the main line. And the most important factor in the front-end business development is the professional staff. So, the main task a leader is supposed to undertake is to organize the staff and to do a good job in coordination in his/her team.

Cultivating the Sense of Team Ownership. The business development of this department involves all the staff. Although they have different posts and are in different areas of expertise, if the sense of team ownership has been cultivated in the team, all the staff will try to work ahead to the same goal.

Being Good at Coordinating. Everyone is designed to do what he/she should do. But that does not necessarily mean cooperation among the staff is satisfying. In order to deal with the market changes and the changes of users' requirements, it is necessary to hold project meetings periodically 
to discuss the plan and the progress. Any change from the cost of products, the market, the technology and the requirements will exert an influence on every task module. The meetings can help all the staff to exchange their ideas so that they may improve what they are doing. The experienced interaction designer will avoid designing the product function which is too hard for a developer, for he/she knows the difficulty in realizing the program in limited time. The excellent visual designer will prepare varied color schemes. The smart development engineer will also code flexibly for any change. If some links discontent with each other, the leader needs to coordinate in order to guarantee the project.

Holding a Reading Party Regularly to Share What Staff Learned. A good leader can not only make reasonable overall arrangements, but also introduce another communication form--reading/sharing party to his/her team. Having a reading party regularly in spare time for his/her team to share with each other, which is of great help for all the staff to save time and improve learning efficiency and get more new knowledge. What's more, the party can enhance the mutual understanding among posts and promote the team cooperation.

\section{Conclusion}

The development of science is just like a giant ship in the floods of times, the technology is the power and the management is to guarantee its correct route. In the development of front-end business, it is the optimal technology management that maximizes the value of this highly-flexible and complex department.

\section{References}

[1] National Research Council: Management of Technology: The Hidden Advantage. [M] New York: National Academic Press, 1987: 15.

[2] Anders Drejer: Frameworks for the Management of Technology: Towards a Contingent Approach. [J] Technology Analysis \&Strategic Management, 1996(1): 9-20.

[3] Edward B. Roberts: Benchmarking Global Strategic Management of Technology. [J] Technology Management, 2001(March-April): 25-26.

[4] Joseph Alois Schumpeter: The Theory of Economic Development. [M] New Bruswick, New Jersey: Translation Books. Translated from the 1911 original German. 1934.

[5] Betz Frederick: Executive Strategy: Strategic Management and Information Technology. [M] New York: John Wiley, 2001.

[6] Norma Harison, Danny Samson: Technology Management: Text and International Cases. [M] Publisher: Wiley, 2004.

[7] George S. Day, Paul J. H. Schoemaker: Wharton on Managing Emerging Technologies. [M] Publisher: McGraw-Hill Publishing Co., 2001.

[8] Daniel p. Petrozzo: The Fast Forward MBA in Technology Management. [M] J.Wiley, 1998.

[9] Wu Guisheng: Management of Technology Innovation. [M] Beijing: China Machine Press, 2011.

[10] Chan Jin: The Technology Management. [M] Beijing: Science Press, 2008.

[11] Wang Guangwei, Feng Songkai: The Frontier Research Report on Technology Management and Technology Innovation. [M] Beijing: Economic Management Press, 2016. 